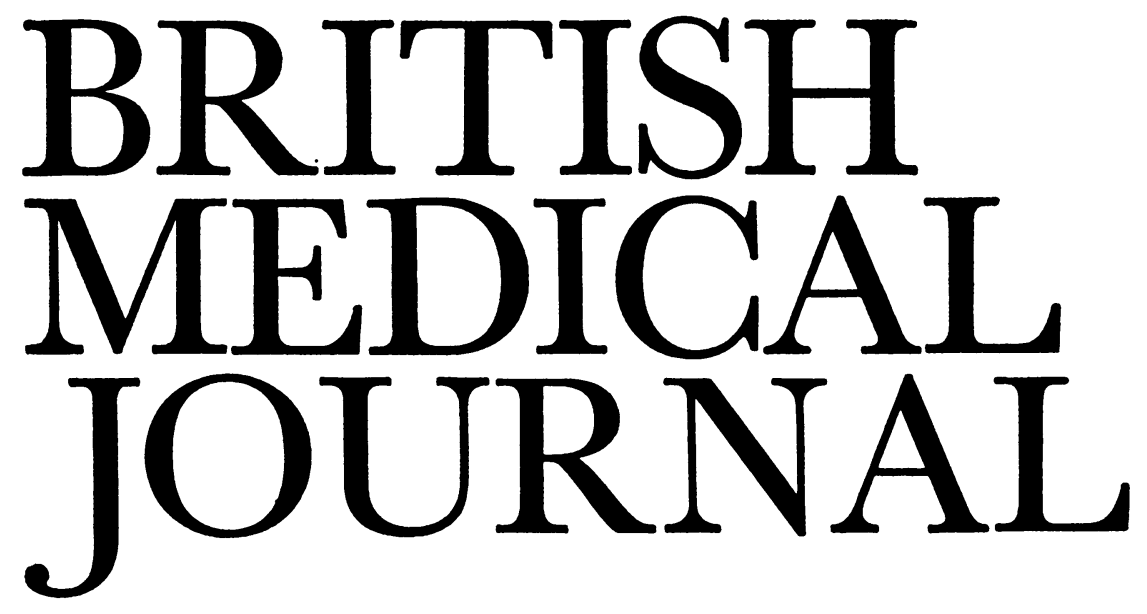

\title{
The Road Forward
}

An emphasis on youth, the value of a united professional organization, a tightening of democratic procedures, and the separation of negotiations on "pay and conditions" from straightforward professional advice to the Health Service authorities, are major themes in Sir Paul Chambers's proposals for reorganizing the B.M.A. His report, published in full in the Supplement (p. 45), had been commissioned by the B.M.A. in 1970 as "a wide ranging" and "searching study of the whole organization from the ground up." Though the B.M.A.'s constitution has been reviewed in recent years ${ }^{2} 3$-and there have been some useful changesSir Paul's exercise is the first major recasting proposed for the Association since its reform in 1903.4

The report is thorough, readable, and uncompromisingly radical. Its proposals are thoughtfully argued through from an analysis of the B.M.A.'s past and present weaknesses to what the Association's objectives should be in the context of a reorganized N.H.S. Sir Paul, who sees wholehearted co-operation with Government in making the N.H.S. work as an essential aim of the Association, is confident that his conclusions, while not the only ones possible, offer the best way out of the B.M.A.'s internal contradictions and difficulties. A federalist solution-a collection of autonomous craft groups with the B.M.A. as co-ordinator-as opposed to the unitary approach favoured in his report would undoubtedly appeal to some doctors. Yet Sir Paul has unhesitatingly proposed unified representation of all the branches of the profession within the B.M.A., with the firm exclusion of non-members from any B.M.A. activities. He argues that this is the best way of presenting a coherent professional policy to the Government, something which the present autonomous approach does not always make easy.

Years of compromise between the conflicting intraprofessional interests, with differences of opinion swept "under the carpet, either temporarily, or hopefully for good," are condemned in the report as having contributed to the confused democratic machinery that hinders the B.M.A. Too much paper, too many and too large committees, overcomplicated procedures, too many lines of communication to the top, items unnecessarily redebated throughout the organization, and unsatisfactory electoral machinery-little escapes Sir Paul's critical eye. Nevertheless, as he pointed out to Council members in presenting his report (Supplement, p. 68), the Association also has a side to be proud of (he mentioned specifically its scientific work), though he deliberately spent no time on cataloguing its features, for his task had been to remedy the weaknesses as he saw them. Having read the tally of the latter an outsider might wonder how the B.M.A. works at all. Of course, by goodwill and give and take, it does. Nevertheless, in a fast evolving environment-the N.H.S. and local government reorganization, Seebohm, and the industrial relations legislation-there is no guarantee that it will continue to do so unless it too adapts.

Many of Sir Paul's suggestions for reorganizing the B.M.A. will probably be accepted with little dissent; changing the Association's regional structure so that it has strong area committees paralleling the new area health authorities is an instance. The accent on equal representation of young doctors will be generally welcomed, though they must justify Sir Paul's faith in them by playing their full part locally and centrally. Some proposals, however, such as the period of service of elected committee members and the idea of a weekly B.M.A. News will give rise to debate. But it is the radical proposals, fundamental to Sir Paul's vision of the future B.M.A., which will provoke most controversy. Only someone from outside the Association with his authority would have had the boldness to appear before its top executive body to recommend both its virtual demise and the abandonment of autonomy. Such is the valueand the price- of an external view.

It will undoubtedly be argued that some of the subtleties of medicopolitics (the nuances of relations between the various branches and organizations within the profession), have been missed. But is this necessarily a weakness in such a radical report? Some will call these subtleties the oil that keeps the wheels turning, others the glue that seizes up the machinery. Sir Paul's contention that the profession must accept the N.H.S. as permanent and that the B.M.A. should proffer its wholehearted support to the Government in helping to improve the Service may not be thought unusual by doctors who have qualified since 1948. Some older doctors, however, will find it difficult to swallow such a total acceptance of nationalized medicine. But this is a central pillar of Sir Paul's recommendations.

With his emphasis on small executive committees, includ- 
ing one to replace the Council, Sir Paul has no doubt been influenced by his experience in business. He is critical of the Representative Body's responsibility for every detail of B.M.A. policy. Its proper role, he maintains, should be to lay down the broad lines of policy, with the Council's successor-the small central executive-having the function of executing the policy in detail. These small committees, some elected by the R.B., others based on a particular craft, would have much power, and their members would have to devote ample time to them if they are to work properly. In a profession which is as heavily committed in its work as are doctors this means that many more doctors than at present would have to be prepared to play a serious part in medicopolitics both locally and nationally. If this led to greater knowledge among doctors of how the Service ticks this would be a gain. The risk is that a situation could develop where the B.M.A. was run almost entirely by professional committeemen supported by the secretariat.

The B.M.A. and the profession owe Sir Paul Chambers a debt of gratitude for his work on their behalf, particularly as it was done without any financial reward. Certainly his wide experience of business management, the obviously painstaking study he has made of other representative organizations, and his extensive consultation within the profession have ensured that his conclusions are solidly based on informed opinion. In presenting his report to the Council Sir Paul said that he had quite deliberately omitted a summary, for he wanted all doctors to read the report as a whole. He feared that summarizing it would lead to hasty judgements from a failure to appreciate the arguments underlying his proposals. The Council is to debate the report at a specially convened meeting in July, when the views of the Association's various standing committees will be available. A Special Representative Meeting will be held in November, at which the profession at large will consider Sir Paul's report and the Council's advice. As well as being published in the B.M.F. the report is being sent by the B.M.A. to non-members.

With the new shadow authorities for the reorganized N.H.S. being set up in 1973 the Association has none too much time to decide whether the hair shirt it bespoke in 1970 is the right fit and fashion for the rest of the century.

1 British Medical fournal Supplement, 1970, 2, 206.

3 British Medical fournal, 1968, 1, 534.

4 British Medical fournal, 1903, 2, 104.

\section{$\mathbf{T}_{3}$ Thyrotoxicosis}

The thyroid gland secretes two hormones, thyroxine $\left(T_{4}\right)$ and triiodothyronine $\left(\mathrm{T}_{3}\right)$. Thyroxine is strongly bound to serum proteins-about $15 \%$ to thyroxine-binding prealbumin (TBPA), 75\% to thyroxine-binding globulin (TBG), and $10 \%$ to serum albumin..$^{1-3}$ Approximately $0.05 \%$ is "free" or unbound. ${ }^{4} \mathrm{~T}_{3}$ is much less strongly bound to proteins than $T_{4}$, so that a much greater proportion will be free. The biological potency of $T_{3}$ is three to four times greater than that of $T_{4}$, but the duration of the effect is shorter. ${ }^{5}$ In normal persons $T_{4}$ and $T_{3}$ are present in the blood in a ratio of about 50 to 1 , and both hormones contribute to the maintenance of a normal metabolic rate. In some individuals $T_{3}$ is the only thyroid hormone secreted.6-8

In hyperthyroid patients both hormones are usually increased and the ratio of $T_{3}$ to $T_{4}$ is higher, though the concentration of $T_{3}$ does not equal that of $T_{4 .} .10$ There is recent evidence to suggest that hyperthyroid patients pass through a stage of high circulating levels of $T_{3}$ before developing overt thyrotoxicosis. ${ }^{11}$ Furthermore, high $T_{3}$ levels may persist in thyrotoxic patients rendered euthyroid with treatment. Such patients have persistent raised serum concentrations of the long-acting thyroid stimulator, and their radioactive iodine uptakes fail to show suppression with triiodothyronine. ${ }^{12}$ In hypothyroidism the serum $T_{3}$ concentration may be within the normal range, and indeed there seems to be sequential failure in the production of first $T_{4}$ and then $T_{3}$ as hypothyroidism becomes more severe. ${ }^{13}$ It has been shown that in about one-half the patients with low serum $T_{4}$ concentrations after iodine-131 therapy a normal metabolic rate is maintained by adequate or raised $T_{3}$ concentrations. ${ }^{14}$

Though no thyrotoxic patients have been encountered with an increase in serum $T_{4}$ but no increase in serum $T_{3}$, clinical thyrotoxicosis does occur with normal serum $T_{4}$ concentrations and an increase in that of $T_{3} .{ }^{13}$ 15-19 This condition has been called $T_{3}$ toxicosis, though the term $T_{3}$ thyrotoxicosis is more appropriate. Most of these individuals have toxic nodular goitres, but more recent reports have included many examples of classical Graves's disease. ${ }^{20}$

Diagnosis in these circumstances presents certain difficulties. The radioactive iodine uptake may not be outside the normal range, as the formation of $T_{3}$ requires less iodine than $T_{4}$. The serum concentrations of protein-bound iodine and thyroxine will be normal as well as the $T_{3}$ resin uptake provided there is no abnormality of thyroxine-binding globulin. However, in none of the patients in whom $T_{3}$ suppression tests have been carried out has the radioactive iodine uptake been suppressible by $\mathrm{T}_{3} .{ }^{14}$

Though the concept of $T_{3}$ thyrotoxicosis is not new, few cases have been reported. Now that methods of measuring $\mathrm{T}_{3}$ are becoming available, ${ }^{15}$ more cases are likely to come to light. Eight further examples have recently been reported from the Mayo Clinic, 21 and an even larger series of 40 patients has now been published from the New York School of Medicine. ${ }^{20}$ Clinically most of them were only mildly thyrotoxic. The conventional laboratory investigations did not confirm the clinical diagnosis of hyperthyroidism. All these patients had normal values for total and free $T_{4}$ and normal levels of thyroxine-binding globulin. It was not until raised serum levels of $T_{3}$ were obtained that the clinical diagnosis received adequate explanation.

There seems little reason to assume that cases of hyperthyroidism with normal serum $T_{4}$ and high serum $T_{3}$ concentrations represent a basically different variety of Graves's disease. The factors favouring $T_{3}$ production have not been fully defined. However, studies in rats that were made iodine-deficient showed a progressive increase in the ratio of $T_{3}$ to $T_{4}$ during the period of iodine deficiency, ${ }^{21}$ and a similar finding has been reported in man when iodine intake is restricted.11 Such a shift in favour of $T_{3}$ production is teleologically sound, since $T_{3}$ has four times the metabolic activity of $\mathrm{T}_{4}$ while utilizing only $75 \%$ as much iodine. A sixfold increase in hormonal effect for the same amount of iodine could thus be achieved, and this would obviously be advantageous in conditions of iodine deficiency. Whether this is relevant to $T_{3}$ thyrotoxicosis is uncertain.

The importance of this entity lies in the need for clinicians to be aware of the existence of a state of hyperthyroidism in which the conventional tests of thyroid function are 